\title{
FUZZY MODEL OPTIMIZATION FOR TIME SERIES DATA USING A TRANSLATION IN THE EXTENT OF MEAN ERROR
}

\author{
${ }^{1,2}$ Nurhayadi, ${ }^{2}$ Subanar, ${ }^{2}$ Abdurakhman and ${ }^{3}$ Agus Maman Abadi \\ ${ }^{1}$ Department of Mathematics and Science Education, Tadulako University, Indonesia \\ ${ }^{2}$ Department of Mathematics and Science, Gadjah Mada University, Indonesia \\ ${ }^{3}$ Department of Mathematics and Science, Yogyakarta State University, Indonesia
}

Received 2014-04-01; Revised 2014-05-30; Accepted 2014-06-02

\begin{abstract}
Recently, many researchers in the field of writing about the prediction of stock price forecasting, electricity load demand and academic enrollment using fuzzy methods. However, in general, modeling does not consider the model position to actual data yet where it means that error is not been handled optimally. The error that is not managed well can reduce the accuracy of the forecasting. Therefore, the paper will discuss reducing error using model translation. The error that will be reduced is Mean Square Error (MSE). Here, the analysis is done mathematically and the empirical study is done by applying translation to fuzzy model for enrollment forecasting at the Alabama University. The results of this analysis show that the translation in the extent of mean error can reduce the MSE.
\end{abstract}

Keywords: Fuzzy Model, Time Series, Model Translation, Forecasting

\section{INTRODUCTION}

Everyday, the individual investors, the managers of stock funds and the financial analyst try to predict the activities of stock price movements based on their professional knowledge or use a tool they have to analyze the stock price. High accuracy is their priority, because an accurate prediction gives more advantages. Therefore, they keep finding ways to predict stock price more accurately.

Some researchers have improved time series modeling using fuzzy method. Fuzzy method is chosen in modeling based on a consideration that fuzzy can accept the input of linguistic variable as experienced by the economist's (Wang, 1997).

The use of fuzzy method in time series forecasting is becoming increasingly widespread. Song and Chissom (1993a; 1993b; 1994) have studied fuzzy application to predict university enrollment. Time series using fuzzy model has been applied to predict peak load electricity demand (Ismail et al., 2009) and has been applied to predict stock price (Egrioglu, 2014; Kao et al., 2013; Nurhayadi et al., 2014; Singh and
Borah, 2014). Rodger (2014) has used fuzzy model to predict the need of natural gas and the energy cost savings in public buildings. While Birek et al. (2014) has applied fuzzy time series for water leakage forecasting in a water supply company.

In addition to the use of fuzzy model that becomes more and more widespread, the researchers have also been trying to improve the quality of forecasting in many ways. Cheng et al. (2006) has generated fuzzy time series model by grouping fuzzy relations based on their antecedents and it gives better results. Giving weights based on the numbers of group members can improve the model accuracy (Yu, 2004; Suhartono and Lee, 2011; Nurhayadi et al., 2012).

Singh and Borah (2013) and Wang et al. (2013) have improved the quality of model using various lengths of intervals. After that, Singh and Borah (2014) have tried to increase the quality using particle swarm optimization.

There are also some researchers who have combined fuzzy method and another method. Allahverdi et al. (2011), Wei et al. (2014) and Sethukkarasi and Kannan (2012) combined fuzzy method and neural network to improve the quality of model. Rahoma et al. (2011)

Corresponding Author: Nurhayadi, Department of Mathematics and Science, Gadjah Mada University, Indonesia 
using neuro fuzzy for the prediction of daily solar radiation. Wavelet has also been used as a preprocessing of fuzzy modeling (Popoola, 2007; Zhu et al., 2014) for the quality improvement.

Lee et al. (2012) said that recent studies show that the newer and more advanced forecasting techniques tend to result in improved forecast accuracy, but no clear evidence shows that any one model can consistently outperform other models in the forecasting competition. The quality comparison between two models is generally difficult to be done, because they usually have different basics in their modeling.

In this study, we increase the optimization by modifying the generated model. Generally, the modeling using fuzzy method does not consider the model precision to the sample data yet. Generated estimation model can be relatively higher or lower than the real data. Therefore, the resulted model needs to be optimized. The optimization can be done by sliding the model up or down.

Agrawal et al. (1995), Argyros and Charis (2003) and Kontaki et al. (2005) have ever used transformation to find the similarity of two sub time series. Graphically, it is done by squeezing two sub time series that have been normalized and then the similarity can be seen from the closeness of each pair of points in two sub time series which are convenient in time. The same way is used to optimize the fuzzy model of time series in this study.

\section{REVIEW OF FUZZY TIME SERIES STUDIES}

Time series modeling using fuzzy inference maps every sample point in time series into fuzzy set and applies the "if-then" fuzzy rule. Wang (1997), Yu (2004) and Nurhayadi et al. (2012) have explained briefly that the formations of weighted fuzzy rules are as follows:

Step 1. Defining fuzzy set containing input and output spaces.

Given a pair of input-output $\left(y_{t-p}, y_{t}\right), t=1,2$, $\ldots ., \mathrm{m}$ where $\left(y_{t-p}, y_{t}\right) \in[\alpha, \beta] \times[\alpha, \beta] \subset R$, with $y_{t-p}$ is the input and $y_{t}$ is the output. In interval $[\alpha, \beta]$, defined a complete fuzzy sets $A_{k}, k=1$, $2,3, \ldots, \mathrm{q}$; where for every $y_{t-p} \in[\alpha, \beta]$ there exists $\mathrm{A}_{\mathrm{k}}$ such that $\mu_{A k}\left(y_{t-p}\right) \neq 0$ and $\mu_{\mathrm{Ak}}\left(\mathrm{y}_{\mathrm{t}-\mathrm{p}}\right)$ is the membership degree of $\mathrm{y}_{\mathrm{t}-\mathrm{p}}$ in fuzzy set $A_{k}$.

Step 2. Generating the rule of every pair of input-output. For every pair of input-output $\left(y_{t-p}, y_{t}\right)$ if-then fuzzy rule is formed as follows:

$$
\text { if } \left.y_{t-p} \text { is } A^{*}\right) \text { then } \hat{y}_{t}=y_{t}
$$

where, $A^{*}$ is fuzzy set $A_{k}$ which has the biggest $\mu_{A k}\left(y_{t-p}\right)$.

Step 3. Constructing of fuzzy rule base.

Group the rules generated in Step 2 based on the similar $A^{*}$. They are the rule's components in part "if" and the consequence of $\bar{y}_{k}$ which is the mean of $y_{t}$ is selected from part "then:

$$
\begin{aligned}
& \text { if }\left(y_{t-p} \text { is } A_{k}\right) \text { then } \hat{y}_{t}=\bar{y}_{t} \\
& k=1,2, \ldots, q
\end{aligned}
$$

Basis of fuzzy rule has to satisfy three conditions below:

- In the rules generated in Step 2, there is no conflict between one rule and another, it means that the similar antecedents do not happen but the different consequences do

- The weights of basis elements are obtained from numbers of groups in Step 2

- Experiences of experts can be included into the basis of fuzzy rules

Step 4. Developing fuzzy system based on the basis of fuzzy rules

For example, obtain $\mathrm{k}$ basis of fuzzy rules, consider singleton fuzzifier, a multiplication in machine of fuzzy inference and defuzzifier of center mean, then use a formula below Equation 1:

$$
\hat{y}_{t}=\frac{\sum_{k=1}^{q} w_{k} \bar{y}_{k} \mu_{A_{k}}\left(y_{t-p}\right)}{\sum_{k=1}^{q} w_{k} \mu_{A_{k}}\left(y_{t-p}\right)}
$$

Where:

$$
\begin{array}{ll}
\hat{y}_{t} & =\text { Value estimation of } \mathrm{y}_{\mathrm{t}} \\
w_{k} & =\text { Weight of fuzzy rule base } \\
\bar{y}_{k} & =\text { Part constant of part "then" and } \\
\mu_{A k}\left(y_{t-p}\right) & =\text { Membership degree of } \mathrm{y}_{\mathrm{t}-\mathrm{p}} \text { in fuzzy set } \mathrm{A}_{\mathrm{k}}
\end{array}
$$

\section{TRANSLATION OF FUZZY MODEL}

There are many things which affect the accuracy of time series fuzzy model, among others are rounding numbers and choosing in consistent way. In order to increase the accuracy, the model needs to be given some advanced treatments. Nurhayadi et al. (2014) have done 
translation to minimize the Mean Absolute Error (MAE) The treatment discussed in this study is a model translation to reduce Mean Square Error (MSE). For example, let $\hat{y}_{1}, \hat{y}_{2}, \ldots ., \hat{y}_{n}$ be the values resulted in prediction using model (1) for set of time series values $y_{1}, y_{2}, \ldots y_{n}$ where Equation 2:

$$
\hat{y}_{1}=y_{1}+e_{1}, \hat{y}_{2}=y_{2}+e_{2}, \ldots ., \hat{y}_{n}=y_{n}+e_{n}
$$

The modeling often yields more prediction points which are over than ones which are under estimate, or vice versa. Certainly, sliding the model slightly upward or downward can affect the error. By choosing movement that gives more error reduction, the MSE will be smaller. This sliding process is shown in Fig. 1.

Furthermore, if the translation is applied to the model in the extent of mean error directing to zero, i.e., $\hat{Y}^{*}=\hat{Y}-\bar{e}$, then MSE of predictors will reach the minimum value of translation.

\section{Theorem 1}

Let $\mathrm{Y}$ be the realization of time series, $\hat{Y}$ is prediction model, $\hat{Y}^{*}=\hat{Y}-\bar{e}$ where $\bar{e}$ is mean error and $e=\hat{Y}-Y$, then $\operatorname{MSE}\left(\hat{Y}^{*}\right) \leq \operatorname{MSE}(\hat{Y})$.

\section{Proof}

If the model $\hat{Y}$ is slid in the extent of $\delta$, i.e., $\hat{Y}^{*}=\hat{Y}+\delta$, then the function $\operatorname{MSE}\left(\hat{Y}^{*}\right)$ is as follows:

$$
\begin{aligned}
& \operatorname{MSE}\left(\bar{Y}^{*}\right) \sum_{i=1}^{n}\left(e_{i}+\delta\right)^{2} \\
& =\sum_{i=1}^{n}\left(e_{i}^{2}+2 e_{i} \delta+\delta^{2}\right) \\
& =\sum_{i=1}^{n} e_{i}^{2}+2 \delta \sum_{i=1}^{n} e_{i}+n \delta^{2}
\end{aligned}
$$

$\operatorname{MSE}\left(\hat{Y}^{*}\right)$ is a quadratic function of $\delta$. The value of this function will be minimum if the derivative to $\delta$ equals to zero, i.e:

$$
\begin{aligned}
& \operatorname{MSE} \frac{d\left(\operatorname{MSE}\left(Y^{*}\right)\right)}{d \delta}=0 \\
& 2 n \delta+2 \sum_{i=1}^{n} e_{i}=0 \\
& \delta=-\frac{2 \sum_{i=1}^{n} e_{i}}{2 n}=-\frac{\sum_{i=1}^{n} e_{i}}{n}=-\bar{e}
\end{aligned}
$$

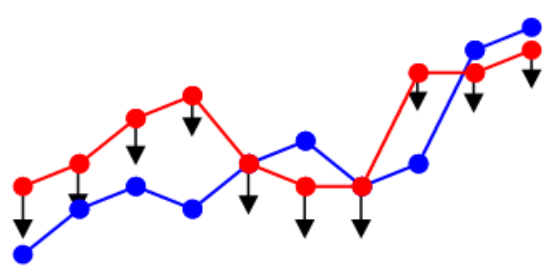

Real values $=$

Prediction $=$

Fig. 1. Model sliding to reduce MSE

So that:

$$
\begin{aligned}
& \operatorname{MSE}(\hat{Y}) \sum_{i=1}^{n} e_{i}^{2} \\
& =\sum_{i=1}^{n}\left(e_{i}+0\right)^{2} \geq \sum_{i=1}^{n}\left(e_{i}-\bar{e}\right)^{2}=\operatorname{MSE}\left(\widehat{Y}^{*}\right)
\end{aligned}
$$

Based on Theorem 1, if the fuzzy model of time series data (1) is translated in the extent of $-\bar{e}$ into Equation 3:

$\hat{y}_{t}=\frac{\sum_{k=1}^{q} w_{k} \bar{y}_{k} \mu_{A_{k}}\left(y_{t-p}\right)}{\sum_{k=1}^{q} w_{k} \mu_{A_{k}}\left(y_{t-p}\right)}-\vec{e}$

Then it is expected to be able to reduce MSE.

\section{VERIFICATIONS AND COMPARISONS}

Ion the method discussed in this study will be compared to other methods. The data used is the enrollment data of Alabama University because this data is widely used by many researchers in time series forecasting.

The first differences of the of enrollment data of Alabama University is normalized using the formula below Equation 4:

$$
z_{t}=\frac{y_{t}^{\prime}-\bar{y}}{s}
$$

$y_{t}^{\prime}=$ First differences of the data

$\bar{y}=$ Mean

$s \quad=$ Standard deviation

The results of normalization in column 4 of Table 1 are applied in the rules at section 2, using $p=1$ and $q=9$. 


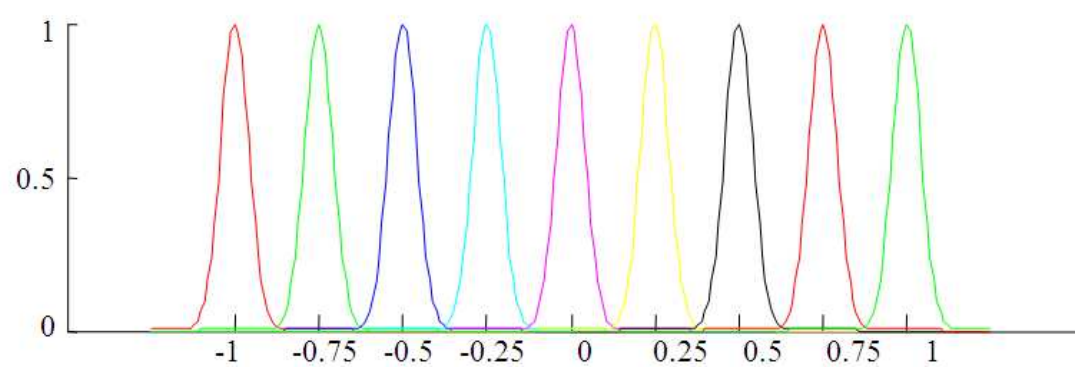

Fig. 2. The fuzzy sets with gaussian membership functions

Step 1. Create 9 fuzzy sets as Fig. 2, with Gaussian membership functions Equation 5:

$\mu_{A_{k}}\left(z_{t-p}\right)=\exp \left(-\frac{1}{2}\left(\frac{z_{t-p}-c_{k}}{s}\right)^{2}\right)$

$k=1,2, \ldots, \mathrm{q}$

$c_{k}=-1,-0.75,-0.5,-0.25,0,0.25,0.5,0.75,1$

$s=(\mathrm{q}-1) / 3$

Step 2. Make the fuzzy rules based on the Fuzzy sets in Step-1 and the data in column 4 of Table $\mathbf{1 .}$

The third column in Table 2 contains the antecedents, they are the part of IF rule. While in the fourth column, there are also consequents which are part of THEN rule.

Step 3. Make the basis of fuzzy rules by grouping rules based on the similar fuzzy sets and consequently the mean values are taken for every group. The weight $\mathrm{w}_{\mathrm{j}}$ is given based on the numbers of rules which arrange it:

Rule 1: If $\mathrm{z}_{\mathrm{t}-1}$ is $\mathrm{A}_{1}$ then $\bar{z}_{t}=-0.9943$ weight $=3$

Rule 2: If $\mathrm{z}_{\mathrm{t}-1}$ is $\mathrm{A}_{2}$ then $\bar{z}_{t}=0.0259$ weight $=1$

Rule 3: If $\mathrm{z}_{\mathrm{t}-1}$ is $\mathrm{A}_{3}$ then $\bar{z}_{t}=-0.1701$ weight $=2$

Rule 4: If $\mathrm{z}_{\mathrm{t}-1}$ is $\mathrm{A}_{4}$ then $\bar{z}_{t}=-1.2577$ weight $=2$

Rule 5: If $\mathrm{z}_{\mathrm{t}-1}$ is $\mathrm{A}_{5}$ then $\bar{z}_{t}=0.7008$ weight $=3$

Rule 6: If $\mathrm{z}_{\mathrm{t}-1}$ is $\mathrm{A}_{6}$ then $\bar{z}_{t}=-0.4693$ weight $=1$

Rule 7: If $\mathrm{z}_{\mathrm{t}-1}$ is $\mathrm{A}_{7}$ then $\bar{z}_{t}=0.0469$ weight $=1$

Rule 8: If $\mathrm{z}_{\mathrm{t}-1}$ is $\mathrm{A}_{8}$ then $\bar{z}_{t}=-0.7458$ weight $=1$

Rule 9: If $\mathrm{z}_{\mathrm{t}-1}$ is $\mathrm{A}_{9}$ then $\bar{z}_{t}=0.7457$ weight $=6$

The prediction is done by substituting $\mathrm{z}_{\mathrm{t}-1}$ and $\bar{z}_{t}$ in

Rule 1 until Rule 9 to the formula (1). The result $\hat{z}_{t}$ is shown in Column 3 of Table 3.
Because the input of the process uses the normalized first differences of the data, then the results of the prediction must be converted using the invers of formula (4) and the invers of the first differentiation. These results are shown in column 4 of Table 4 . In the same time, the translation using formula (3) results in prediction values shown in column 5 .

From the comparison of the prediction results in column 4 and 5 with the actual values in column 6 , we can see that the translation in the extent of mean error can decrease the MSE.

Table 1. The actual enrollment data, difference-1 and normalization

\begin{tabular}{|c|c|c|c|}
\hline Year $\mathrm{t}$ & Actual $y_{t}$ & 1st difference $y_{t}^{\prime}$ & Norm $z_{t}$ \\
\hline 1971 & 13,055 & 508 & 0.4039 \\
\hline 1972 & 13,563 & 304 & 0.0469 \\
\hline 1973 & 13,867 & 829 & 0.9656 \\
\hline 1974 & 14,696 & 764 & 0.8519 \\
\hline 1975 & 15,460 & -149 & -0.7458 \\
\hline 1976 & 15,311 & 292 & 0.0259 \\
\hline 1977 & 15,603 & 258 & -0.0336 \\
\hline 1978 & 15,861 & 946 & 1.1704 \\
\hline 1979 & 16,807 & 112 & -0.2891 \\
\hline 1980 & 16,919 & -531 & -1.4143 \\
\hline 1981 & 16,388 & -955 & -2.1562 \\
\hline 1982 & 15,433 & 64 & -0.3731 \\
\hline 1983 & 15,497 & -352 & -1.1010 \\
\hline 1984 & 15,145 & 18 & -0.4536 \\
\hline 1985 & 15,163 & 821 & 0.9516 \\
\hline 1986 & 15,984 & 875 & 1.0461 \\
\hline 1987 & 16,859 & 1291 & 1.7741 \\
\hline 1988 & 18,150 & 820 & 0.9499 \\
\hline 1989 & 18,970 & 358 & 0.1414 \\
\hline 1990 & 19,328 & 9 & -0.4693 \\
\hline 1991 & 19,337 & -461 & -1.2918 \\
\hline 1992 & 18,876 & & \\
\hline
\end{tabular}


The results of the forecast based on the proposed models, compared with the results Song and Chissom (1993), Sullivan and Woodall (1994), Chen (1996) and Cheng et al. (2008) are shown in Table 5.

Table 2. Fuzzy rule

\begin{tabular}{lrlr}
\hline $\mathrm{t}-1$ & $\mathrm{Z}_{\mathrm{t}-1}$ & Fuzzy set & \multicolumn{1}{c}{$\mathrm{Z}_{\mathrm{t}}$} \\
\hline 1971 & 0.4039 & $\mathrm{~A} 7$ & 0.0469 \\
1972 & 0.0469 & A5 & 0.9656 \\
1973 & 0.9656 & A9 & 0.8519 \\
1974 & 0.8519 & A8 & -0.7458 \\
1975 & -0.7458 & A2 & 0.0259 \\
1976 & 0.0259 & A5 & -0.0336 \\
1977 & -0.0336 & A5 & 1.1704 \\
1978 & 1.1704 & A9 & -0.2891 \\
1979 & -0.2891 & A4 & -1.4143 \\
1980 & -1.4143 & A1 & -2.1562 \\
1981 & -2.1562 & A1 & -0.3731 \\
1982 & -0.3731 & A4 & -1.1010 \\
1983 & -1.1010 & A1 & -0.4536 \\
1984 & -0.4536 & A3 & 0.9516 \\
1985 & 0.9516 & A9 & 1.0461 \\
1986 & 1.0461 & A9 & 1.7741 \\
1987 & 1.7741 & A9 & 0.9499 \\
1988 & 0.9499 & A9 & 0.1414 \\
1989 & 0.1414 & A6 & -0.4693 \\
1990 & -0.4693 & A3 & -1.2918 \\
\hline
\end{tabular}

In Fig. 3, the graph of actual values is indicated by the blue plot and the graph of predictions is indicated by the red one.

Based on the results from Table 5, the proposed model has a smaller Root Mean Square Error (RMSE) and less average error than the other models.

Table 3. The predictions using weighted fuzzy model

\begin{tabular}{lrr}
\hline $\mathrm{t}-1$ & $\mathrm{Z}_{\mathrm{t}-\mathrm{t}}$ & $\hat{\mathrm{z}}_{\mathrm{t}}$ \\
\hline 1971 & 0.4039 & 0.0390 \\
1972 & 0.0469 & 0.7008 \\
1973 & 0.9656 & 0.7457 \\
1974 & 0.8519 & -0.4820 \\
1975 & -0.7458 & 0.0259 \\
1976 & 0.0259 & 0.7008 \\
1977 & -0.0336 & 0.7008 \\
1978 & 1.1704 & 0.7457 \\
1979 & -0.2891 & -1.2576 \\
1980 & -1.4143 & -0.9943 \\
1981 & -2.1562 & -0.9943 \\
1982 & -0.3731 & -0.7891 \\
1983 & -1.1010 & -0.9943 \\
1984 & -0.4536 & -0.1701 \\
1985 & 0.9516 & 0.7457 \\
1986 & 1.0461 & 0.7457 \\
1987 & 1.7741 & 0.7457 \\
1988 & 0.9499 & 0.7457 \\
1989 & 0.1414 & -0.2116 \\
1990 & -0.4693 & -0.1701 \\
\hline
\end{tabular}

Table 4. The results of enrollment prediction

\begin{tabular}{|c|c|c|c|c|c|}
\hline $\mathrm{t}$ & $\hat{\mathrm{z}}_{\mathrm{t}}$ & $\hat{y}_{t}^{\prime}$ & $\hat{y}_{t}$ & $\hat{y}_{t}^{*}$ & $\mathrm{y}_{\mathrm{t}}$ \\
\hline 1972 & 0.039 & 299.4726 & & & \\
\hline 1973 & 0.7008 & 677.6638 & 13,862 & 13,834 & 13,867 \\
\hline 1974 & 0.7457 & 703.333 & 14,545 & 14,517 & 14,696 \\
\hline 1975 & -0.482 & 1.7408 & 15,399 & 15,371 & 15,460 \\
\hline 1976 & 0.0259 & 292 & 15,462 & 15,434 & 15,311 \\
\hline 1977 & 0.7008 & 677.6665 & 15,603 & 15,575 & 15,603 \\
\hline 1978 & 0.7008 & 677.6652 & 16,281 & 16,253 & 15,861 \\
\hline 1979 & 0.7457 & 703.3333 & 16,539 & 16,511 & 16,807 \\
\hline 1980 & -1.2576 & -441.4974 & 17,510 & 17,482 & 16,919 \\
\hline 1981 & -0.9943 & -291 & 16,478 & 16,450 & 16,388 \\
\hline 1982 & -0.9943 & -291 & 16,097 & 16,069 & 15,433 \\
\hline 1983 & -0.7891 & -173.7338 & 15,142 & 15,114 & 15,497 \\
\hline 1984 & -0.9943 & -291 & 15,323 & 15,295 & 15,145 \\
\hline 1985 & -0.1701 & 179.9924 & 14,854 & 14,826 & 15,163 \\
\hline 1986 & 0.7457 & 703.331 & 15,343 & 15,315 & 15,984 \\
\hline 1987 & 0.7457 & 703.3333 & 16,687 & 16,659 & 16,859 \\
\hline 1988 & 0.7457 & 703.3333 & 17,562 & 17,534 & 18,150 \\
\hline 1989 & 0.7457 & 703.3304 & 18,853 & 18,825 & 18,970 \\
\hline 1990 & -0.2116 & 156.2444 & 19,673 & 19,645 & 19,328 \\
\hline 1991 & -0.1701 & 179.9992 & 19,484 & 19,456 & 19,337 \\
\hline 1992 & & & 19,517 & 19,489 & 18,876 \\
\hline Mean & & & 28 & 0 & \\
\hline MSE & & & 135023 & 134238 & \\
\hline RMSE & & & 367 & 366 & \\
\hline
\end{tabular}


Nurhayadi et al. / Journal of Mathematics and Statistics 10 (2): 267-274, 2014

Table 5. Comparisons of the prediction results for enrollment with different models

\begin{tabular}{lllllll}
\hline Year & Actual & Song (1993a; 1993b) & Sullivan and Woodall (1994) & Chen (1996) & Cheng et al. (2008) & Proposed method \\
\hline 1971 & 13,055 & & & & & \\
1972 & 13,563 & 14,000 & 13,500 & 14,000 & $13,680.5$ & 13,834 \\
1973 & 13,867 & 14,000 & 14,500 & 14,000 & $13,731.3$ & 14,517 \\
1974 & 14,696 & 14,000 & 14,500 & 14,000 & $13,761.2$ & 15,371 \\
1975 & 15,460 & 15,500 & 15,231 & 15,500 & $15,194.6$ & 15,434 \\
1976 & 15,311 & 16,000 & 15,563 & 16,000 & $15,374.8$ & 15,575 \\
1977 & 15,603 & 16,000 & 15,500 & 16,000 & $15,359.9$ & 16,253 \\
1978 & 15,861 & 16,000 & 15,500 & 16,000 & $16,410.3$ & 16,511 \\
1979 & 16,807 & 16,000 & 15,500 & 16,000 & $16,436.1$ & 17,482 \\
1980 & 16,919 & 16,813 & 16,684 & 16,833 & $17,130.7$ & 16,450 \\
1981 & 16,388 & 16,813 & 16,684 & 16,833 & $17,141.9$ & 16,069 \\
1982 & 15,433 & 16,789 & 15,500 & 16,833 & $15,363.8$ & 15,114 \\
1983 & 15,497 & 16,000 & 15,563 & 16,000 & $15,372.1$ & 15,295 \\
1984 & 15,145 & 16,000 & 15,563 & 16,000 & $15,378.5$ & 14,826 \\
1985 & 15,163 & 16,000 & 15,563 & 16,000 & $15,343.3$ & 15,315 \\
1986 & 15,984 & 16,000 & 15,563 & 16,000 & $15,345.1$ & 16,659 \\
1987 & 16,859 & 16,000 & 15,500 & 16,000 & $16,448.4$ & 17,534 \\
1988 & 18,150 & 16,813 & 16,577 & 16,833 & $17,135.9$ & 18,825 \\
1989 & 18,970 & 19,000 & 19,500 & 19,000 & $18,915.0$ & 19,645 \\
1990 & 19,328 & 19,000 & 19,500 & 19,000 & $18,997.0$ & 19,456 \\
1991 & 19,337 & 19,000 & 19,500 & 19,000 & $19,032.8$ & 19,489 \\
1992 & 18,876 & & 19,000 & 19,000 & $19,033.7$ & 366 \\
RMSE & & 650 & 621 & 638 & 438 &
\end{tabular}

Table 6. Actual and forecasting with translation results for the enrollment

\begin{tabular}{|c|c|c|c|c|c|}
\hline Year & Actual & Song- $\overline{\mathrm{e}}$ & Sullivan- $\overline{\mathrm{e}}$ & Chen- $\overline{\mathrm{e}}$ & Cheng- $\overline{\mathrm{e}}$ \\
\hline 1971 & 13,055 & & & & \\
\hline 1972 & 13,563 & $13,930.7$ & $13,642.5$ & $13,923.1$ & $13,805.7$ \\
\hline 1973 & 13,867 & $13,930.7$ & $14,642.5$ & $13,923.1$ & $13,856.5$ \\
\hline 1974 & 14,696 & $13,930.7$ & $14,642.5$ & $13,923.1$ & $13,886.9$ \\
\hline 1975 & 15,460 & $15,430.7$ & $15,373.5$ & $15,423.1$ & $15,319.8$ \\
\hline 1976 & 15,311 & $15,930.7$ & $15,705.5$ & $15,923.1$ & $15,500.0$ \\
\hline 1977 & 15,603 & $15,930.7$ & $15,642.5$ & $15,923.1$ & $15,485.1$ \\
\hline 1978 & 15,861 & $15,930.7$ & $15,642.5$ & $15,923.1$ & $16,535.5$ \\
\hline 1979 & 16,807 & $15,930.7$ & $15,642.5$ & $15,923.1$ & $16,561.3$ \\
\hline 1980 & 16,919 & $16,743.7$ & $16,826.5$ & $16,756.1$ & $17,255.9$ \\
\hline 1981 & 16,388 & $16,743.7$ & $16,826.5$ & $16,756.1$ & $17,267.1$ \\
\hline 1982 & 15,433 & $16,719.7$ & $15,642.5$ & $16,756.1$ & $15,489.0$ \\
\hline 1983 & 15,497 & $15,930.7$ & $15,705.5$ & $15,923.1$ & $15,497.3$ \\
\hline 1984 & 15,145 & $15,930.7$ & $15,705.5$ & $15,923.1$ & $15,503.7$ \\
\hline 1985 & 15,163 & $15,930.7$ & $15,705.5$ & $15,923.1$ & $15,468.5$ \\
\hline 1986 & 15,984 & $15,930.7$ & $15,705.5$ & $15,923.1$ & $15,470.3$ \\
\hline 1987 & 16,859 & $15,930.7$ & $15,642.5$ & $15,923.1$ & $16,573.6$ \\
\hline 1988 & 18,150 & $16,743.7$ & $16,719.5$ & $16,756.1$ & $17,261.1$ \\
\hline 1989 & 18,970 & $18,930.7$ & $19,642.5$ & $18,923.1$ & $19,040.2$ \\
\hline 1990 & 19,328 & $18,930.7$ & $19,642.5$ & $18,923.1$ & $19,122.2$ \\
\hline 1991 & 19,337 & $18,930.7$ & $19,642.5$ & $18,923.1$ & $19,158.0$ \\
\hline 1992 & 18,876 & & & $18,923.1$ & $19,158.9$ \\
\hline RMSE & & 646.7 & 605.1 & 633.7 & 420 \\
\hline
\end{tabular}




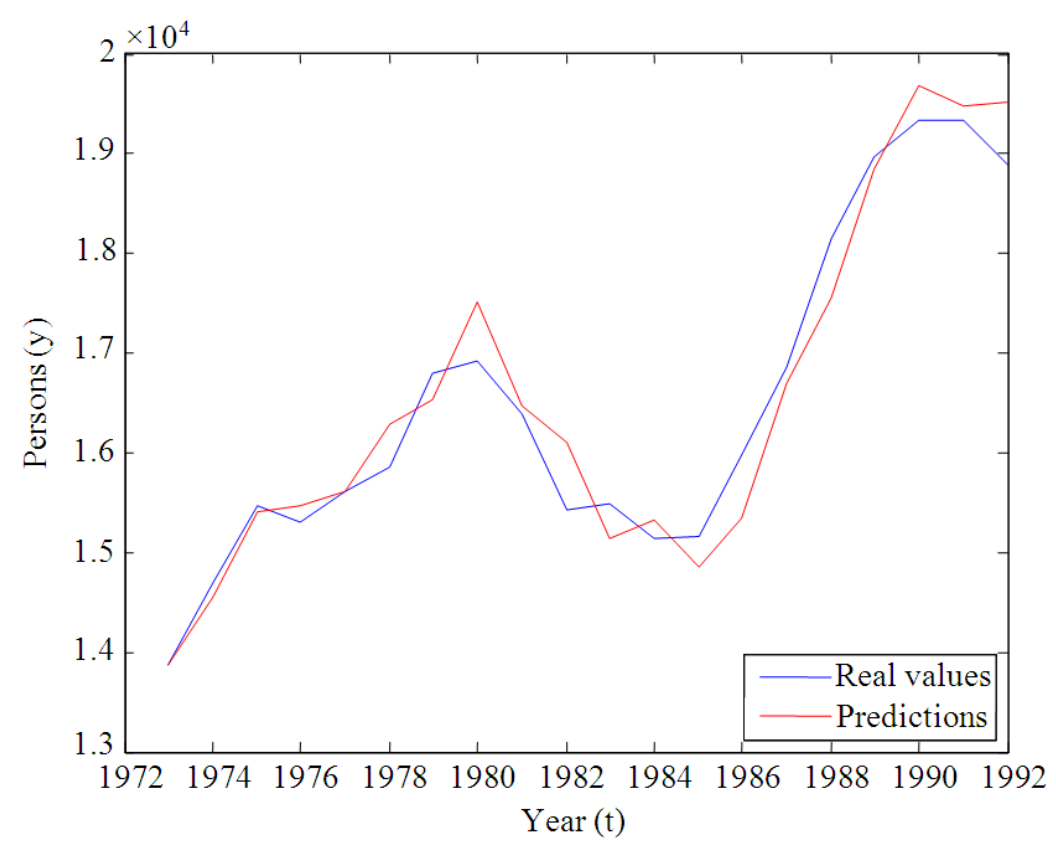

Fig. 3. The actual value of the enrollment and prediction results

If the translation is applied to models generated by other researchers, then the RMSE in each model will also decline and it means that the MSE declines too. This result is shown in Table 6.

Based on the results from Table 6, the translation of model can reduce the forecasting done by other researchers.

\section{CONCLUSION}

Theoretically, a translation in the extent of mean error can reduce MSE. The translation in the extent of mean error applied to model (1) that uses Gaussian membership function gives a better result than the other models and it is shown in Table 5. If this translation is applied to each of other models, then the RMSE of each model will also decline.

\section{REFERENCES}

Agrawal, R., K.I. Lin, H.S. Sawhney and K. Shim, 1995. Fast similarity search in the presence of noise, scaling and translation in time-series databases. Proceedings of the 21th International Conference on Very Large Data Bases, (LDB' 95), Morgan Kaufmann Publishers Inc. San Francisco, CA, USA., pp: 490-501.
Allahverdi, A., A. Tunali, H. Isik, H. Kahramanli, 2011. A takagi-sugeno type neuro-fuzzy network for determining child anemia. Expert Syst. Applic., $\quad 38$ : 7415-7418. $\quad$ DOI: 10.1016/j.eswa.2010.12.083

Argyros, T. and E. Charis, 2003. Efficient subsequence matching in time series databases under time and amplitude transformations. Proceedings of 3rd IEEE International Conference on Data Mining, Nov. 19-22, IEEE Xplore Press, pp: 481-484. DOI: 10.1109/ICDM.2003.1250957

Birek, L., D. Petrovic and J. Boylan, 2014. Water leakage forecasting: The application of a modified fuzzyevolving algorithm. Applied Soft Comput., 14: 305-315. DOI: 10.1016/j.asoc.2013.05.021

Chen, S.M., 1996. Forecasting enrollments based on fuzzy time-series. Fuzzy Sets Syst., 81: 311-319. DOI: 10.1016/0165-0114(95)00220-0

Cheng, C.H., T.L. Chen and C.H. Chiang, 2006. Trend-weighted fuzzy time-series model for TAIEX forecasting. Proceedings of the 13th International Conference on Neural Information Processing, Oct. 3-6, Springer Berlin Heidelberg, Hong Kong, China, pp: 469-477. DOI: 10.1007/11893295_52 
Cheng, C., T. Chen, H.J. Teoh and C. Chiang, 2008. Fuzzy time-series based on adaptive expectation model for taiex forecasting. Expert Syst. Applic., 34: 1126-1132. DOI: 10.1016/j.eswa.2006.12.021

Egrioglu, E., 2014. PSO-based high order time invariant fuzzy time series method: Application to stock exchange data. Econom. Modell., 38:633-639. DOI: 10.1016/j.econmod.2014.02.017

Ismail, Z., A. Yahya and K.A. Mahpol, 2009. Forecasting peak load electricity demand using statistics and rule based approach. Am. J. Applied Sci., 6: 1618-1625. DOI: 10.3844/ajassp.2009.1618.1625

Kao, J.L., C.C. Chiu, C. Lu and J. LiYang, 2013. Integration of nonlinear independent component analysis and support vector regression for stock price forecasting. Neurocomputing, 99:534-542. DOI: 10.1016/j.neucom.2012.06.037

Kontaki, M., A.N. Papadopoulos and M. Yannis, 2005. Similarity Search in Time-Series Databases, Encyclopedia of Database Technologies and Applications. IDEA Group Publishing.

Lee, M.H., M.E. Nor, Suhartono, H.J. Sadaei and N.H.A. Rahman, 2012. Fuzzy time series: An application to tourism demand forecasting. Am. J. Applied Sci., 9: 132-140. DOI: 10.3844/ajassp.2012.132.140

Nurhayadi, Subanar, Abdurakhman and A.M Abadi,. 2012. Weighted fuzzy rule base to modeling time series data and its application in prediction of stock prices. Proceedings of the International Conference on Mathematics, Statistics and Its Applications, Nov. 19-21, Bali, Indonesia.

Nurhayadi, Subanar, Abdurakhman and A.M Abadi, 2014. Fuzzy model translation for time series data in the extent of median error and its application. Applied Math. Sci., 8: 2113-2124. DOI: 10.12988/ams.2014.42114

Popoola, A., 2007. Fuzzy-wavelet method for time series analysis. Delft University of Technology, Netherland.

Rahoma, W.A., U.A. Rahoma and A.H. Hassan, 2011. Application of neuro-fuzzy techniques for solar radiation. J. Comput. Sci., 7: 1605-1611. DOI: 10.3844/jcssp.2011.1605.1611

Rodger, J.A., 2014. A fuzzy nearest neighbor neural network statistical model for predicting demand for natural gas and energy cost savings in public buildings. Expert Syst. Applic., 41: 1813-1829. DOI: 10.1016/j.eswa.2013.08.080
Sethukkarasi, R. and A. Kannan, 2012. A dynamic temporal neuro fuzzy inference system for mining medical databases. J. Comput. Sci., 8: 1924-1931. DOI: $10.3844 /$ jcssp.2012.1924.1931

Singh, P. and B. Borah, 2013. An efficient time series forecasting model based on fuzzy timeseries. Eng. Applic. Artif. Intell., 26: 2443-2457. DOI: 10.1016/j.engappai.2013.07.012

Singh, P. and B. Borah, 2014. Forecasting stock index price based on M-factors fuzzy time series and particle swarm optimization. Int. J. Approximate Reason., 55: 812-833. DOI: 10.1016/j.ijar.2013.09.014

Song, Q. and B.S. Chissom, 1993a. Fuzzy time-series and its models. Fuzzy Sets Syst., 54: 269-277. DOI: 10.1016/0165-0114(93)90372-O

Song, Q. and B.S. Chissom, 1993b. Forecasting enrollments with fuzzy time series part I. Fuzzy Sets Syst., 54: 1-9. DOI: 10.1016/0165-0114(93)90355-L

Song, Q. and B.S. Chissom, 1994. Forecasting enrollments with fuzzy time series-Part II. Fuzzy Sets Syst., 62: 1-8. DOI: 10.1016/01650114(94)90067-1

Suhartono and M.H. Lee, 2011. A hybrid approach based on winter's model and weighted fuzzy time series for forecasting trend and seasonal data. J. Math. Stat., 7: 177-183. DOI: 10.3844/jmssp.2011.177.183

Sullivan, J.H. and W.H. Woodall, 1994. A comparison of fuzzy forecasting and markov modeling. Fuzzy Sets Syst., 64: 279-293. DOI: 10.1016/01650114(94)90152-X

Wang, L.X, 1997. A Course in Fuzzy System and Control. 1st Edn., Prentice Hall, Inc, New Jersey.

Wang, L., X. Liu and W. Pedrycz, 2013, Effective intervals determined by information granules to improve forecasting in fuzzy time series. Expert Syst. Applic., 40: 5673-5679. DOI: 10.1016/j.eswa.2013.04.026

Wei, L., C. Cheng and H. Wu, 2014. A hybrid ANFIS based on n-period moving average model to forecastTAIEX stock. Applied Soft Comput., 19: 86-92. DOI: 10.1016/j.asoc.2014.01.022

Yu, H.K., 2004. Weighted fuzzy time series models for TAIEX forecasting. Physica, 349: 609-624. DOI: 10.1016/j.physa.2004.11.006

Zhu, L., Y. Wang and Q. Fan, 2014. MODWT-ARMA model for time series prediction. Applied Math. Modell., 38: 1859-1865. DOI: 10.1016/j.apm.2013.10.002 